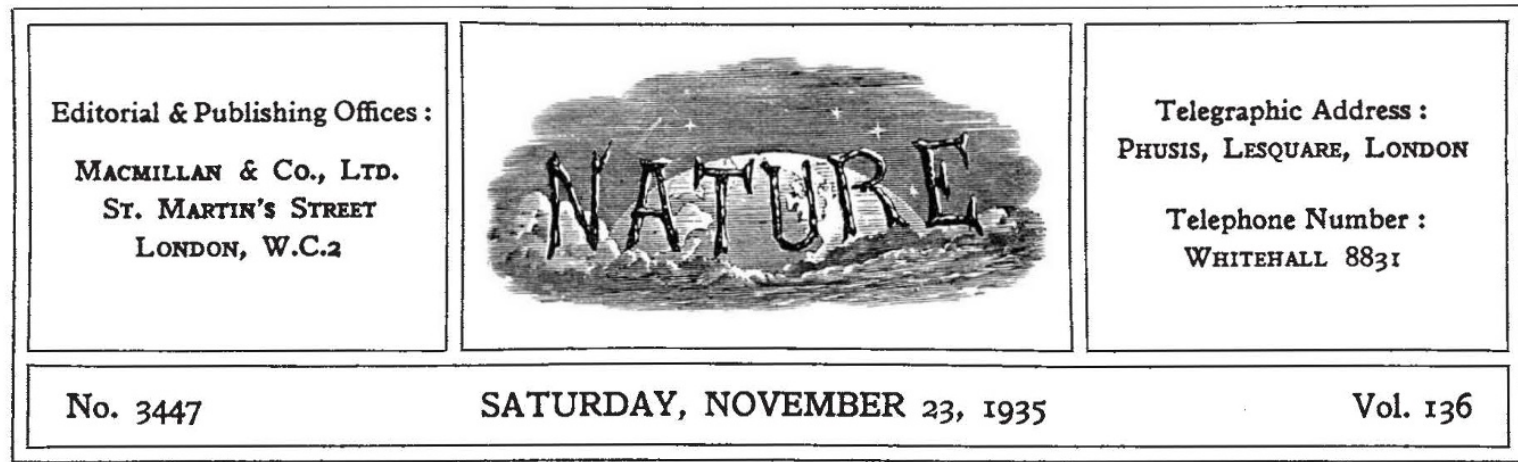

\title{
Economics of Plenty*
}

$\mathrm{F}$ EW problems have astonished the modern world so much as the apparent paradox of "poverty in the midst of plenty" yet, as Sir Josiah Stamp pointed out in his Norman Lockyer Lecture to the British Science Guild, delivered on November 13 and entitled "The Calculus of Plenty", the problem is by no means new, for just a hundred years ago, Carlyle could write that "In the midst of plethoric plenty, the people perish". As the years have gone on, the term 'plenty', while still covering the glaring maladjustment of things made, longed for but unused, has gradually widened in content to mean much more. In the last few years, it has become so nebulous and over-suggestive as to be, in Sir Josiah Stamp's words, almost an intellectual menace. The conception for which it stands, however, is in all conscience, he said, serious enough, though we should not be overawed or confused by it. The rigorous analytical examination to which Sir Josiah subjected the term 'plenty' in the course of his lecture provides an important contribution to the elucidation of the various problems involved, which only too often are lumped together to the confusion of clear thinking. Adopting a main threefold classification with various sub-heads, he classified 'plenty' as first that of physical or scientific potentiality; secondly, as that of unused or unmarketed production; and thirdly, that of unused capacity.

The plenty of potentiality is mainly a conception of the engineer and man of science, and it was developed to its greatest extent by the exponents of technocracy, who have left a sinister trail of dreams and pseudo-statistics over the whole field of thought and inquiry. Generally speaking, it

* The Calculus of Plenty. By Sir Josiah Stamp. (The Norman Lockyer Lecture, 1935.) Pp. 35. (London: British Science Guild, 1935.) 18 . expresses the facts of output in terms of reduced man-power for a given output. But the crude figures of engineering potentiality need to be qualified before the net figures of economic potentiality are deduced. It may well be that on the manufacturing side all the attendant supplies and processes cannot be speeded up to correspond, or the full and even load postulated may not really be available. Further, even supposing a considerably lower price is possible for the larger quantities available, after allowing for every production difficulty, it is not certain that the amount will be taken by the public at that price or even at any price. It might be a boon to make 100 fire grates with the ease with which one is now made, and yet not really a greater boon in any realistic sense to make 1,000 for every one now. Technical possibility has to be considered against a background of economic and psychological relativity. A further serious limitation will arise if in fact there are only one or two of the new machines in existence, and the bulk of supply comes from older equipment. In this event, the alleged plenty does not actually exist, nor is it actually potential ; it is only hypothetically or ultimately potential. The current concept of plenty popularly linked in almost causative association with poverty is fed from three main sources : the concept of things not hitherto made but now capable of being made, the concept of things already made and standing unused, and the concept of things that have not but could have been made.

Large dynamic ideas are scientifically dangerous if they remain unmeasured. Technological and scientific conceptions of plenty are capable of measurement and quantitative statement, but an accepted technique for this purpose is still lacking, 
and no recognised units of productivity have yet been devised which are capable of being fairly aggregated and compared. The problem, however, goes much further than the mere measurement of plenty, since successive increments of productivity of apparent equality in measurement may have different values in practice. It may be, for example, that an invention can only be brought into full use gradually ; fuller utilisation of unused capacity may involve greater proportionate expense for each unit, or increased supplies may only be demanded if the price is reduced.

The technocrats made grossly excessive claims about the potentialities of science and invention, nearly always stated quantitatively, and with great apparent exactness, thus conveying an impression of realisable plenty were it not for someone's stupidity or the faults of society. Some of the processes of technocratic computation, it would seem, assumed that machinery would be kept working 24 hours a day, or that what was true for an isolated process was true for a whole industry.

The gross possible theoretical or technical capacity based on engineering ideas has to be brought down to the more important economic capacity in several stages. First there is the operating margin. A 100 per cent use is in practice unattainable; a part amounting to something like 20 per cent must serve as a reserve for breakdown, repairs, irregularity of supplies, etc.

Secondly, there is unco-ordinated surplus capacity, since industries are not so perfectly integrated as to make possible a flow of production which will keep all stages fully employed. An intensified demand may quickly bring out some limiting factor. Allied to this, there is seasonal surplus capacity, and plant cannot be deemed to have a yearly capacity equal to its seasonal capacity multiplied by the full term.

Thirdly, it is possible that two industries may have surplus capacity technically equal yet vastly different in practical potentiality. For example, people might be desiring radio sets more and more and pianos less and less, and not generally both. Abundant purchasing power means much greater demand for the one, very slight extra demand for the other. Clearly potential 'plenty' cannot be regarded as the aggregate of these two unused sets of plant. Further, the advance of science and invention may render certain productive units obsolescent, or capital may be invested in production which is economically misplaced.
Consideration must also be given to the demand side. Suppose there is an efficient up-to-date plant for the production of a certain article which is only 70 per cent utilised, but which could be fully utilised without difficulty. Then we could only call the 30 per cent "plenty in the midst of poverty" if additional employment or spending power enhances total demand at the former price, so that an enhanced total supply produced at the same cost is marketed. But if increased spending power gives a relatively less increased demand for this article and the increased supply is at a relatively higher cost, we certainly could not.

The destruction of actually produced wealth when men are in need strikes the imagination much more than mere unused capacity; it seems so wanton. But this, as Sir Josiah Stamp pointed out, is by no means entirely a modern phenomenon, for the throwing overboard of Eastern produce to maintain the price of the remainder has in a former century been the producers' strike against an elastic demand schedule.

Stocks 'carried over' have not all the same quality. A glut of plums in Worcestershire not worth the cost of picking and getting to market is not effectively 'plenty', though if there is a canning factory then it may well be plenty. Here, of course, the demand schedule for canned fruit is quite another thing than that for fresh fruit. Then there is obviously a 'quality of position', for a surplus of tons of produce in Australia can well be different from tons in Smithfield. Perhaps the best-known example of the actual destruction of 'plenty' is the recent burning of coffee in Brazil, but not everybody has realised that the probable cause of the whole episode was an attempt on the part of producers, not merely to maintain prices but even to raise them. The excess supply of wheat of late years seems enormous when stated absolutely in bushels, but if it is measured in relation to total consumption, namely, $2.05 \mathrm{per}$ cent, it becomes quite reasonable.

Sir Josiah Stamp also discussed the measurement of invention 'plenty'. Often innovations take a long time to get fully adopted if their margin of advantage is not revolutionary. The laboratory case may be proved up to the hilt, the engineer may be positive but the capital market is slow in moving: and, in Sir Josiah's view, there is no reason to suppose that socially-owned capital would be more progressive and risk-taking than privately-subscribed capital, so as to reduce the lag between an idea and its practical development. 